JIAHUI LIU, Graduate student ${ }^{1}$

E-mail: liu.jiahui@mail.scut.edu.cn

PEIQUN LIN, Ph.D. ${ }^{1}$

(Corresponding author)

E-mail: pqlin@scut.edu.cn

PETER J. JIN, Ph.D. ${ }^{2}$

E-mail: peter.j.jin@rutgers.edu

1 School of Civil Engineering and Transportation,

South China University of Technology

381 Wushan Road, Tianhe District, Guangzhou 510640,

P.R. China

2 Department of Civil and Environmental Engineering,

School of Engineering,

Rutgers, The State University of New Jersey,

96 Frelinghuysen Road, Piscataway, NJ 08854, USA
Intelligent Transport Systems (ITS)

Preliminary Communication

Submitted: 17 Dec. 2015

Accepted: 21 Sep. 2016

\title{
MODELLING AND SIMULATION OF COOPERATIVE CONTROL FOR BUS RAPID TRANSIT VEHICLE PLATOON IN A CONNECTED VEHICLE ENVIRONMENT
}

\begin{abstract}
The aim of this paper is to develop a cooperative control model for improving the operational efficiency of Bus Rapid Transit (BRT) vehicles. The model takes advantage of the emerging connected vehicle technology. A connected vehicle centre is established to assign a specific reservation time interval and transmit the corresponding dynamic speed guidance to each BRT vehicle. Furthermore, a set of constraints have been set up to avoid bus queuing and waiting phenomena in downstream BRT stations. Therefore, many BRT vehicles are strategically guided to form a platoon, which can pass through an intersection with no impedance. An actual signalized intersection along the Guangzhou BRT corridor is employed to verify and assess the cooperative control model in various traffic conditions. The simulation-based evaluation results demonstrate that the proposed approach can reduce delays, decrease the number of stops, and improve the sustainability of the BRT vehicles.
\end{abstract}

\section{KEY WORDS}

Bus Rapid Transit; cooperative control model; connected vehicles; vehicle platoon;

\section{INTRODUCTION}

In the last two decades, different BRT systems with different characteristics and success levels have been implemented in metropolitan areas worldwide. In general, a BRT system at present is defined as a collective way of land transportation based on the functional features of Light Rail Transit, and it also benefits from the economic advantages and flexibility of the buses. Hence, it can offer a collective service of land transportation in a more comfortable and faster way by rubber-tired vehicles [1-3]. It has also been highlighted that the BRT can provide more economical services as a high-quality massive transportation system [4].

Numerous matched facilities are employed to improve the service quality of a BRT system, including external automatic ticket checker, platform-level boarding station and exclusive bus lane. The use of Intelligent Transportation System (ITS) to provide real-time information (e.g. the waiting time for the next bus) to passengers is also of great importance. Although a BRT system is equipped with several advanced facilities, BRT vehicles will still experience additional travel time because of the "stop and go" control rhythm of traffic signals at intersections. An incompetent traffic signal scheme also increases fuel consumption, exhaust pollution, and engine and brake wear. This severely prevents transit managements from fully exploiting BRT's advantages, including rapidness, efficiency and sustainability.

Many researchers recommend Transit Signal Priority (TSP) for transit buses at signalized intersections. The potential benefits of TSP under various conditions have been evaluated by many studies [5-9]. However, one major shortcoming is its adverse impacts on side streets that limit the promotion of TSP. To date, the majority of existing studies focus on developing better TSP logic, including improving the predictive accuracy of bus arrival time, employing new TSP strategies and enhancing selective priority, to maximize the benefits of TSP and to reduce the negative impacts on non-transit users. However, the practice of TSP is often limited due to high cost of the technology that works cooperatively between transit and traffic systems [10]. A challenge faced by some agencies is the contradiction between engineering need and practical management. 
For instance, highly frequent TSP priority requests, especially in a BRT system, degrade a well-designed signal scheme.

In contrast, only a few studies have been dedicated to developing dynamic speed guidance on the BRT vehicles, based on two-way communications between vehicle and roadside infrastructure. The lack of information about the "future" state of the traffic signal increases the number of stops, fuel consumption, and engine and brake wear. In an ideal situation, if the upcoming signal status was known, the speed could be adjusted for a timely arrival at the green light.

Abu-Lebdeh [11-13] pointed out that using dynamic speed control can improve the operation of signalized networks. Yang [14] developed arterial velocity planning algorithms that provide dynamic speed advice to each individual driver. Asadi [15] proposed the use of upcoming traffic signal information within the vehicle's adaptive cruise control system to reduce idle time at stop lights and fuel consumption. Mahler [16] evaluated statistically the velocity-planning algorithms that minimize idling time behind red lights based on probabilistic traffic-signal timing models.

In summary, the previous studies on dynamic speed guidance were addressed based on the traditional environment. To the best of our knowledge, no effort has been made to strategically guide BRT vehicles to pass through a signalized intersection using the emerging connected vehicle technology. Therefore, this study attempts to fill such research gap. Most BRT systems have adopted many ITS technologies, such as Automatic Vehicle Location (AVL) technology, GPS and wireless communication technology (3G, WLAN, etc.). By nature, BRT systems are good candidates to promote the connected vehicle system. Thus, this paper offers good demonstration of applying the connected vehicle technology in a BRT system.

The main contents in this study include: (1) a cooperative control method for BRT vehicle platoon in a connected vehicle environment; (2) the model mechanism and implementation process of the proposed method; and (3) simulation-based evaluation results of the new approach in an actual signalized intersection under various traffic conditions.

\section{METHODOLOGY}

\subsection{Model assumptions}

The cooperative control model is built on the following assumptions.

1) At each BRT station and its adjacent intersections, a connected vehicle centre (CVC) connected with several roadside units is established to coordinate the movement of BRT vehicles. The CVC can observe all BRT vehicles' trajectories through traffic detection technologies such as AVL and GPS. The signal scheme is also available to CVC.

2) Each BRT vehicle tries to connect with CVC and transmits its destination, position, speed and acceleration to the CVC periodically. The measurement errors of BRT vehicle states are small enough to be neglected. In addition, every BRT vehicle receives and follows the corresponding instructions of CVC.

3) The communication status between CVC and BRT vehicles is excellent. The packet loss rate of data is within 5\% (packet loss rate of WLAN network), and the transmission time is small enough to be ignored.

4) There is an exclusive median bus lane along a BRT corridor. Thus, the social vehicle interference on BRT vehicles is not considered.

\subsection{Initial reservation time interval}

CVC distributes a specific initial reservation time interval for an individual BRT vehicle, as soon as the vehicle departs from a BRT station. A BRT vehicle's initial reservation time interval is calculated based on its position, speed and the state of current signal light. However, it does not consider the constraints of the front vehicles. Suppose $r_{i}$ is the time stamp when the traffic light turns red at the $i$-th time, and $g_{i}$ is the time stamp when the traffic light turns green at the $i$-th time. In consideration of the dissipation time due to queuing vehicles, the effective green time interval is defined as Equation 1:

$\left[g_{i}-L T_{i}, r_{i+1}\right]$

The lost green time $L T_{i}$ caused by queuing vehicles is calculated by the shock wave theory. The queue length is estimated based on the position of BRT vehicles. Detailed algorithms can be found in the model developed by Goodall [17].

If a BRT vehicle acceleration (deceleration) capability and speed limits are considered (no car-following constraints), the arrival time interval upon reaching the stop line is as follows:

$\left[t_{0}+\frac{I_{1}-I_{0}}{V_{\max }}+\frac{\left(V_{\max }-V_{0}\right)^{2}}{2 a_{\max } V_{\max }}\right.$,
$\left.t_{0}+\frac{I_{1}-I_{0}}{V_{\min }}+\frac{\left(V_{\min }-V_{0}\right)^{2}}{2 a_{\min } V_{\min }}\right]$

where $t_{0}$ and $V_{0}$ represent the initial time stamp and speed of a BRT vehicle, respectively; $I_{0}$ and $I_{1}$ are longitudinal coordinate of the vehicle and the stop line, respectively; $V_{\min }$ and $V_{\max }$ denote the minimum and maximum speed; and $a_{\min }$ and $a_{\max }$ represent the minimum deceleration and maximum acceleration, respectively.

The initial reservation time interval of a currently detected BRT vehicle is demonstrated as follows, 


$$
\begin{aligned}
& {\left[t_{0}+\frac{I_{1}-I_{0}}{V_{\max }}+\frac{\left(V_{\max }-V_{0}\right)^{2}}{2 a_{\max } V_{\max }},\right.} \\
& \left.t_{0}+\frac{I_{1}-I_{0}}{V_{\min }}+\frac{\left(V_{\min }-V_{0}\right)^{2}}{2 a_{\min } V_{\min }}\right] \\
& \cap\left[g_{1}-L T_{1}, r_{2}\right] \cap\left[g_{2}-L T_{2}, r_{3}\right] \cap \ldots\left[g_{i}-L T_{i}, r_{i+1}\right]
\end{aligned}
$$

which is the overlap of the effective green time interval and the arrival time interval.

\subsection{Target state of BRT vehicles in a platoon}

The initial state and the target state of $p_{i}^{j}$ are respectively denoted as:

$$
\begin{aligned}
& \operatorname{IS}\left(v_{0}\left(p_{i}^{j}\right), t_{0}\left(p_{i}^{j}\right), I_{0}\left(p_{i}^{j}\right)\right), \\
& \operatorname{TS}\left(v_{1}\left(p_{i}^{j}\right), t_{1}\left(p_{i}^{j}\right), I_{1}\left(p_{i}^{j}\right)\right)
\end{aligned}
$$

where $p_{i}^{j}$ is the $j$-th vehicle in the $i$-th platoon; $v_{0}\left(p_{i}^{j}\right), t_{0}\left(p_{i}^{j}\right)$ and $I_{0}\left(p_{i}^{j}\right)$ represent the current speed, time stamp and longitudinal coordinate of the $p_{i}^{j}$ respectively when it is detected by CVC; and $v_{1}\left(p_{i}^{i}\right), t_{1}\left(p_{i}^{i}\right)$ and $I_{1}\left(p_{i}^{j}\right)$ denote the speed, time stamp and longitudinal coordinate of the $p_{i}^{j}$ respectively when arriving at the stop line.

When a BRT vehicle is departing from a station, its initial reservation time interval needs to be calculated by CVC. If the initial reservation time interval is an empty set, the vehicle cannot be treated as a cooperative control object. Otherwise, CVC is responsible to determine the associated platoon of the currently detected vehicle. And then CVC will recalculate its target state based on the two cases.

\section{Case 1}

The closest BRT vehicle in front of it belongs to the $j$-th vehicle of the $i$-th platoon. If the following constraints are met, then the currently detected BRT vehicle can join the $i$-th platoon. Otherwise, this vehicle is regarded as the first vehicle of the next platoon.

1) Arrival time interval constraint:

$$
f t d_{\min }-t_{1}\left(p_{i}^{j}\right) \leq \frac{S_{0}+v_{1}\left(p_{i}^{j}\right) T+\operatorname{Len}\left(p_{i}^{j}\right)}{V_{1}\left(p_{i}^{j}\right)}
$$

where $f t d_{\min }$ is the lower bound of the initial reservation time interval. $S_{0}$ is the basic standstill distance. $T$ represents the minimum time headway for safety. $\operatorname{Len}\left(p_{i}^{j}\right)$ is the length of $p_{i}^{j}$.

2) Vehicle platoon size constraint:

$$
\sum_{j=0}^{N_{i}} \delta\left(p_{i}^{j}\right)<N_{s}
$$

where $N_{i}$ is the number of vehicles in $i$-th platoon. $\delta\left(p_{i}^{j}\right)$ is a binary variant, $\delta\left(p_{i}^{j}\right)=1$ means $p_{i}^{j}$ will dwell at the downstream bus station and $\delta\left(p_{i}^{j}\right)=0$ means the opposite situation. $N_{\mathrm{s}}$ represents the number of sub-stops in the downstream bus station.

3) Admission constraint:

$$
\sum_{j=0}^{N_{i}} R_{c}\left(p_{i}^{j}\right)=0
$$

where $R_{c}\left(p_{i}^{j}\right)$ is a binary variant; $R_{c}\left(p_{i}^{j}\right)=1$ means the route of $p_{i}^{j}$ is the same as that of the currently detected BRT vehicle; and $R_{c}\left(p_{i}^{i}\right)=0$ means the opposite situation.

Case 2

No vehicle is ahead of the currently detected BRT vehicle or the front vehicle is not a cooperative control object. Then this BRT vehicle is regarded as the leading vehicle of the next platoon. This vehicle must meet the headway constraint:

$t_{1}\left(p_{i+1}^{0}\right)-t_{1}\left(p_{i}^{0}\right) \geq D_{T}+\omega$

where $p_{i}^{0}$ is the first vehicle of the $i$-th platoon; $D_{T}$ represents the average dwell time of the downstream bus station; $\omega$ is an additional time gap that allows some stochastic variations.

In the proposed cooperative control model, each BRT vehicle in the same platoon has equal target speed. Therefore, the target state of $p_{i}^{j}$ is determined as follows:

$$
\left\{\begin{array}{l}
v_{1}\left(p_{i}^{j}\right)=v_{1}\left(p_{i}^{0}\right) \\
t_{1}\left(p_{i}^{j}\right)=t_{1}\left(p_{i}^{0}\right)+\sum_{k=1}^{j} h_{i}^{k} \\
l_{1}\left(p_{i}^{j}\right)=I_{1}\left(p_{i}^{0}\right) \\
h_{i}^{j}=\frac{S_{0}+v_{1}\left(p_{i}^{0}\right) T+\operatorname{Len}\left(p_{i}^{j-1}\right)}{v_{1}\left(p_{i}^{0}\right)}
\end{array}\right.
$$

where $h_{l}^{j}$ is the time headway between the $j$-th vehicle and the $(j-1)$-th vehicle in the $i$-th platoon.

\subsection{Cooperative Control Model for BRT Vehicles}

According to the initial state and the target state of a BRT vehicle, CVC tries to find a three-segment-linear speed profile for the vehicle. The solution space and the availability of the three-segment-linear speed profile have been verified. More specific explanations were demonstrated in our previous work [18-19].

In the first step, the vehicle manoeuvres variable motion with acceleration (deceleration) $a_{1}$, and the finished time stamp of the first step is $t t_{1}$. In the second step, the vehicle manoeuvres variable motion with acceleration (deceleration) $a_{2}$ and the finished time stamp of the second step is $t t_{2}$. In the third step, the vehicle manoeuvres uniform motion until it passes the stop line, and the finished time stamp of the third step is $t_{1}$.

$$
\begin{aligned}
& \operatorname{IS}\left(v_{0}\left(p_{i}^{j}\right), t_{0}\left(p_{i}^{j}\right), I_{0}\left(p_{i}^{j}\right)\right) \frac{\text { folow a three-segment-linear }}{\longrightarrow} \\
& \operatorname{TS}\left(v_{1}\left(p_{i}^{j}\right), t_{1}\left(p_{i}^{j}\right), I_{1}\left(p_{i}^{j}\right)\right)
\end{aligned}
$$

All BRT vehicles are expected to meet the following two principles to complete the cooperative control 
process: (1) Each vehicle needs to reduce the time of variable motion to ensure the platoon stability; (2) all vehicles must observe car-following constraints at any time. The speed function of $j$-th BRT vehicle in $i$-th platoon is denoted as $f\left(p_{i}^{j}, t\right)$, where $f$ is a piecewise continuous differentiable function as mentioned above, that is subjected to the following constraints: Integral Constraint:

$\int_{t_{0}}^{t_{1}} f\left(p_{i}^{j}, t\right) d t=I_{1}\left(p_{i}^{j}\right)-I_{0}\left(p_{i}^{j}\right)$

Formula 11 can be rewritten as follows:

$\left\{\begin{array}{c}v_{\text {med }}\left(p_{i}^{j}\right)=v_{0}\left(p_{i}^{j}\right)+a_{1}\left(p_{i}^{j}\right)\left[t t_{1}\left(p_{i}^{j}\right)-t_{0}\left(p_{i}^{j}\right)\right] \\ v_{1}\left(p_{i}^{j}\right)=v_{\text {med }}\left(p_{i}^{j}\right)+a_{2}\left(p_{i}^{j}\right)\left[t t_{2}\left(p_{i}^{j}\right)-t t_{1}\left(p_{i}^{j}\right)\right]\end{array}\right.$

$$
\left\{\begin{array}{l}
I_{\mathrm{s} 1}=\frac{v_{\text {med }}^{2}\left(p_{i}^{j}\right)-v_{0}^{2}\left(p_{i}^{j}\right)}{2 a_{1}\left(p_{i}^{j}\right)} \\
I_{\mathrm{s} 2}=\frac{v_{1}^{2}\left(p_{i}^{j}\right)-v_{\text {med }}^{2}\left(p_{i}^{j}\right)}{2 a_{2}\left(p_{i}^{j}\right)} \\
I_{\mathrm{s} 3}=v_{1}\left(p_{i}^{j}\right)\left[t_{1}\left(p_{i}^{j}\right)-t t_{2}\left(p_{i}^{j}\right)\right] \\
I_{\mathrm{s} 1}+I_{\mathrm{s} 2}+I_{\mathrm{s} 3}=I_{1}\left(p_{i}^{j}\right)-I_{0}\left(p_{i}^{j}\right)
\end{array}\right.
$$

where $v_{\text {med }}\left(p_{i}^{j}\right)$ is the transition velocity; $I_{s 1}, I_{s 2}$ and $I_{s 3}$ are the travel distances of the three stages, respectively; $a_{1}$ and $a_{2}$ are the acceleration (deceleration) of the first two stages.

Differential Constraint:

$f\left(p_{i}^{j}, t\right) \in\left[a_{\min }, a_{\max }\right]$

Magnitude Constraint:

$f\left(p_{i}^{j}, t\right) \in\left[V_{\min }, V_{\max }\right]$

Boundary Constraint:

$$
\left\{\begin{array}{l}
f\left(p_{i}^{j}, t_{0}\right)=v_{0}\left(p_{i}^{j}\right) \\
f\left(p_{i}^{j}, t_{1}\right) v_{1}\left(p_{i}^{j}\right)
\end{array}\right.
$$

Longitudinal Safety Distance Constraint:

$$
\begin{aligned}
& \int_{0}^{x} g\left(p_{i}^{j-1}, t\right) d t-\int_{0}^{x} f\left(p_{i}^{j}, t\right) d t \geq \\
& \geq \frac{g^{2}\left(p_{i}^{j-1}, t\right)-f^{2}\left(p_{i}^{j}, t\right)}{-2 a_{\min }}+ \\
& +f\left(p_{i}^{j}, t\right) \varepsilon+\operatorname{Len}\left(p_{i}^{j-1}\right)+S_{0}
\end{aligned}
$$

where g represents the speed function of the front vehicle; $\varepsilon$ is the reaction time. Furthermore, the driving comfort is expressed as follows:

$$
\begin{aligned}
& \sigma\left(p_{i}^{j}\right)=\left\{\frac{1}{T_{i}^{j}} \int_{0}^{T_{i}^{j}}\left[a_{i}^{j}(t)-\bar{a}_{i}^{j}\right]^{2} d t\right\}^{\frac{1}{2}} \\
& \bar{a}_{i}^{j}=\frac{v_{1}\left(p_{i}^{j}\right)-v_{0}\left(p_{i}^{j}\right)}{T_{i}^{j}}
\end{aligned}
$$

$$
T_{i}^{j}=t_{1}\left(p_{i}^{j}\right)-t_{0}\left(p_{i}^{j}\right)
$$

where $\sigma\left(p_{i}^{j}\right), \bar{a}_{i}^{j}$ and $T_{i}^{j}$ are acceleration interference, average acceleration, and duration of variable motion of $p_{i}^{j}$, respectively. In this study, the duration of variable motion and the acceleration interference are chosen as the optimized indices. Finally, the completed mathematical model is described as follows:

$\min F=\alpha \frac{t t_{2}\left(p_{i}^{j}\right)-t_{0}\left(p_{i}^{j}\right)}{t_{1}\left(p_{i}^{j}\right)-t_{0}\left(p_{i}^{j}\right)}+\frac{\sigma\left(p_{i}^{j}\right)}{\sigma \max }$

s.t. $11-20$

where $\alpha$ is a coefficient, and $\sigma_{\max }$ is the maximum acceleration interference. This is a non-linear programming problem with multi constraints, and the genetic algorithm is employed to search for the suboptimal solution.

\section{MODEL IMPLEMENTATION}

The state of the art microscopic traffic simulation software VISSIM5.2 64bit edition is used as the traffic simulation environment [20]. This study also develops special computational and logical software, namely, parallel double networks simulation test-bed (PDNSTB), to exchange data and control information with VISSIM via VISSIM COM based on the Visual Studio 2010 platform. The real-time position, speed, acceleration, destination, passengers of BRT vehicles and signal scheme are available in the self-developed software. In other words, it could be considered as a self-built connected vehicle environment. The model mechanism and implementation process are shown in Figure 1.

\section{CASE STUDY}

The Guangzhou BRT (GBRT) system has been used as a case study. The GBRT system has an intelligent dispatching system that covers all BRT vehicles as well as BRT stations along the BRT corridor. The dispatch centre can obtain real-time speed and location of the BRT vehicles using GPS and radio frequency identification devices equipped onboard the bus. The wireless hosted network is responsible for scheduling the system data as well as exchanging real-time information with passengers through the $\mathrm{H} 3 \mathrm{C}$ enterprise-class WLAN products. Hence, the GBRT system has basic characteristics of a connected vehicle system.

The study site is a signalized intersection formed by Zhongshan Avenue (GBRT corridor) and Gangwan Road in Huangpu District, Guangzhou, as shown in Figure 2. The adjacent BRT stations in the east and west approaches are the Xiasha Station and the Zhujiangcun Station, respectively. The intersection adopts a four-phase fixed-time signal scheme and the intersection channelization is shown in Figure 2 (the yellow arrow represents the exclusive median bus lane). 


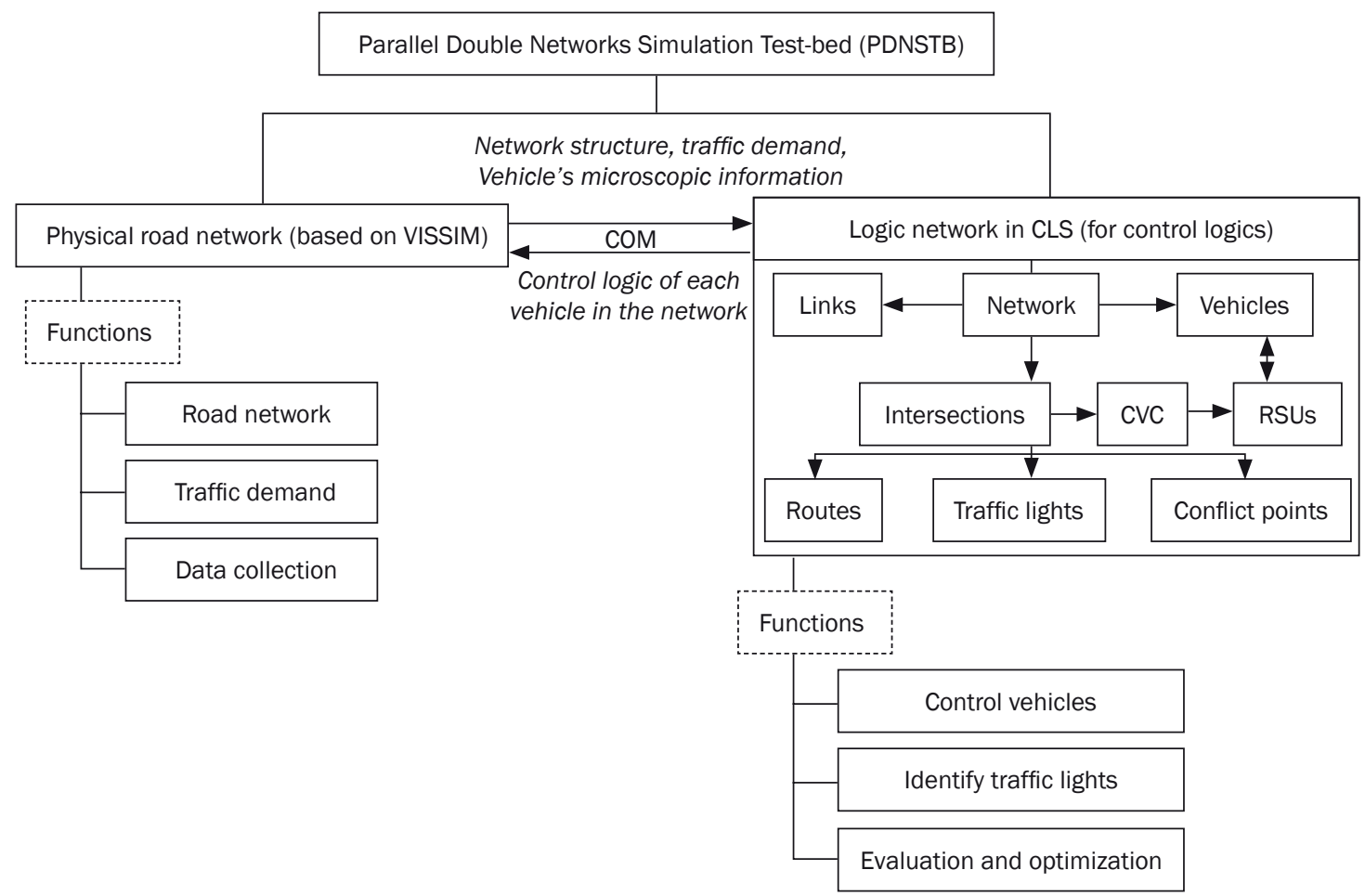

a) Parallel double networks of simulation test-bed (PDNSTB)

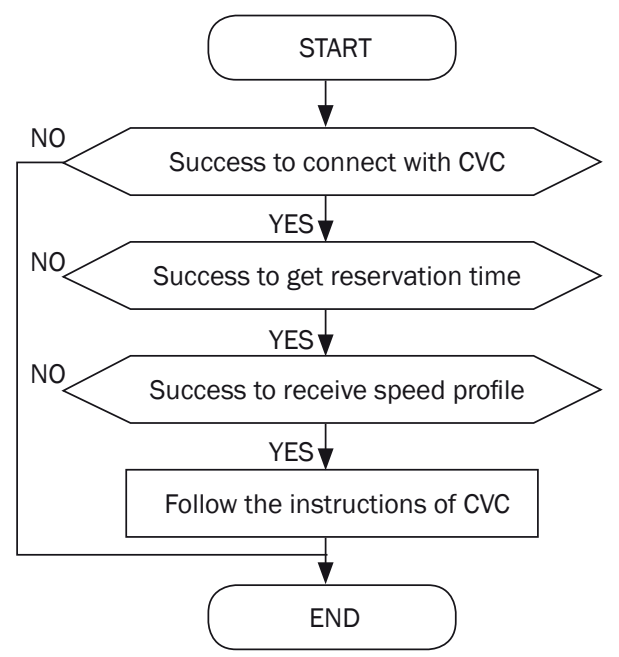

b) Cooperative control process

Figure 1 - Model mechanism and implementation process

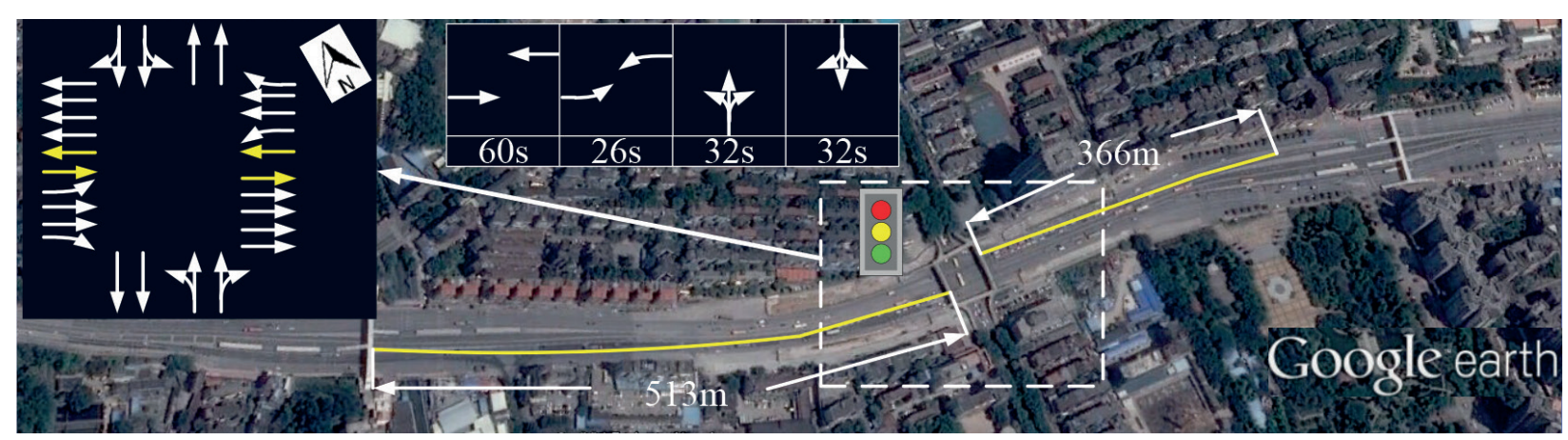

Figure 2 - Intersection layout and signal scheme 
There is a two-way two-lane dedicated bus lane in the middle of the Zhongshan Avenue. An extra overtaking lane around the BRT stations is available to reduce the probability of bus queuing and waiting phenomena. Moreover, a pedestrian overpass is built to connect the central BRT station with sidewalk. The Zhujiangcun Station consists of two sub-stations, each of which includes three docking bays. The Xiasha Station has one sub-station with three docking bays. In the morning peak hours, nine BRT lines operate from the Zhujiangcun Station to the Xiasha Station, and five in the opposite direction. Actual departure frequency of each BRT line and the traffic volume of the intersection in the morning peak hours have been collected and coded

Table 2 - Simulation-based evaluation results in the simulation model. The main simulation parameters are shown in Table 1.

Table 1 - Simulation Parameters

\begin{tabular}{||c|c|c|c||}
\hline $\begin{array}{c}\text { Simulation } \\
\text { parameter }\end{array}$ & Value & $\begin{array}{c}\text { Simulation } \\
\text { parameter }\end{array}$ & Value \\
\hline \hline$V_{\max }$ & $45 \mathrm{~km} / \mathrm{h}$ & $T$ & $2 \mathrm{~s}$ \\
\hline$V_{\min }$ & $20 \mathrm{~km} / \mathrm{h}$ & $\mathrm{s}_{O}$ & $2 \mathrm{~m}$ \\
\hline $\begin{array}{c}\text { Desired } \\
\text { speed }\end{array}$ & $35 \mathrm{~km} / \mathrm{h}$ & $\alpha$ & 2 \\
\hline$a_{\max }$ & $2 \mathrm{~m} / \mathrm{s}^{2}$ & $\delta_{\max }$ & $1 \mathrm{~m} / \mathrm{s}^{2}$ \\
\hline$a_{\min }$ & $-2.5 \mathrm{~m} / \mathrm{s}^{2}$ & $\omega$ & $10 \mathrm{~s}$ \\
\hline$D_{T}$ & $28 \mathrm{~s}$ & $\begin{array}{c}\text { Other } \\
\text { parameters }\end{array}$ & $\begin{array}{c}\text { VISSIM's de- } \\
\text { fault setting }\end{array}$ \\
\hline
\end{tabular}

\begin{tabular}{||l|l|c|c||}
\hline \multicolumn{1}{|c|}{ Direction } & \multicolumn{1}{|c|}{ Comparison factors } & Without cooperative control & With cooperative control \\
\hline \hline & Number of buses & 108 & 108 \\
\hline & Average number of stops & 0.6 & 0.33 \\
\hline & Average delay time & $33.2 \mathrm{~s}$ & $30.8 \mathrm{~s}$ \\
\hline & Fuel consumption & $2.4 \mathrm{gal}$ & $2.18 \mathrm{gal}$ \\
\hline & CO emissions & $167.89 \mathrm{~g}$ & $154.58 \mathrm{~g}$ \\
\hline & Number of buses & 60 & 60 \\
\hline & Average number of stops & 0.61 & 0.37 \\
\hline & Average delay time & $34.7 \mathrm{~s}$ & $1.23 \mathrm{gal}$ \\
\hline & Fuel consumption & $1.33 \mathrm{gal}$ & $86.31 \mathrm{~g}$ \\
\hline
\end{tabular}

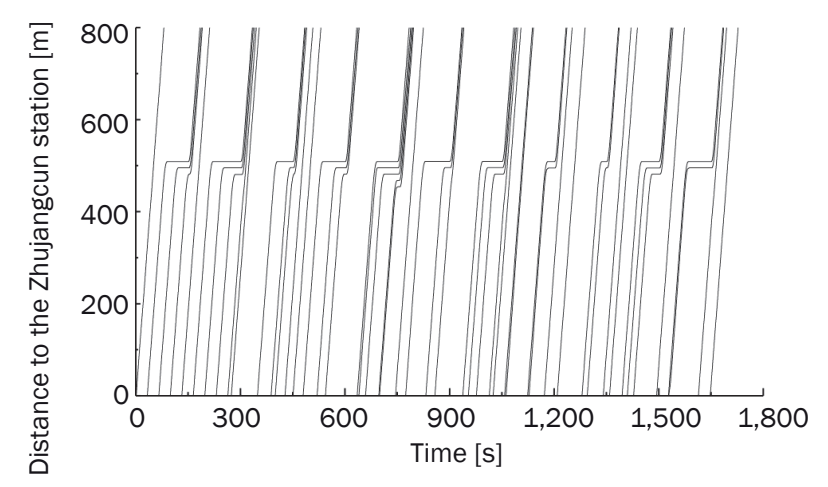

a) Bus trajectories without cooperative control

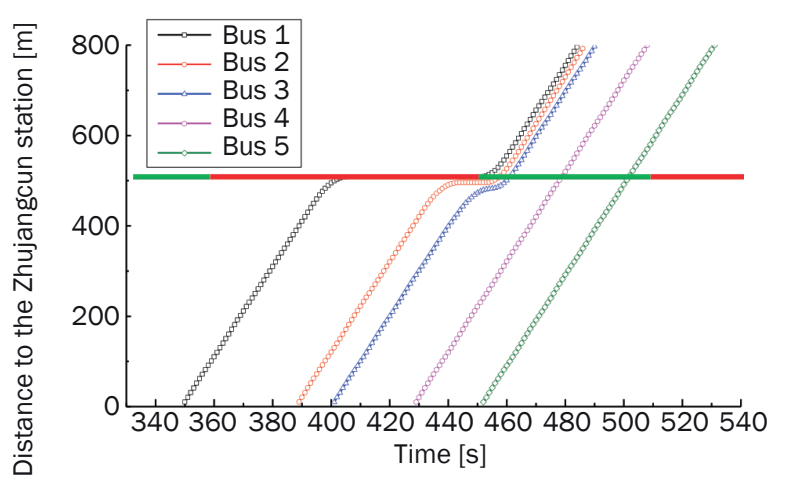

c) Typical bus trajectories without cooperative control

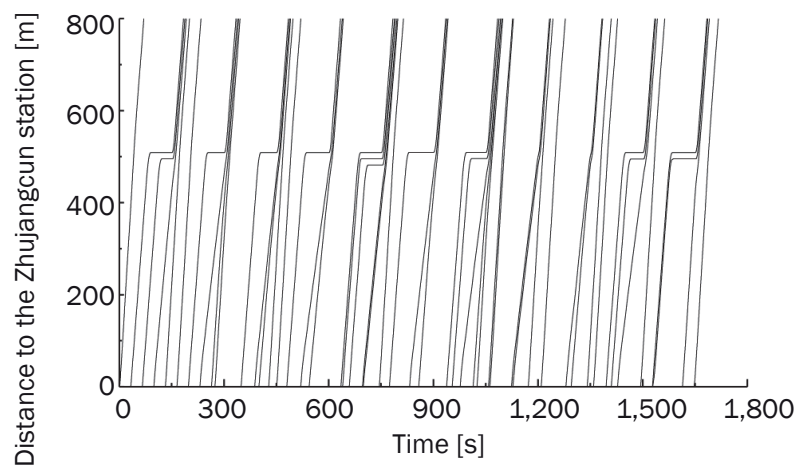

b) Bus trajectories with cooperative control

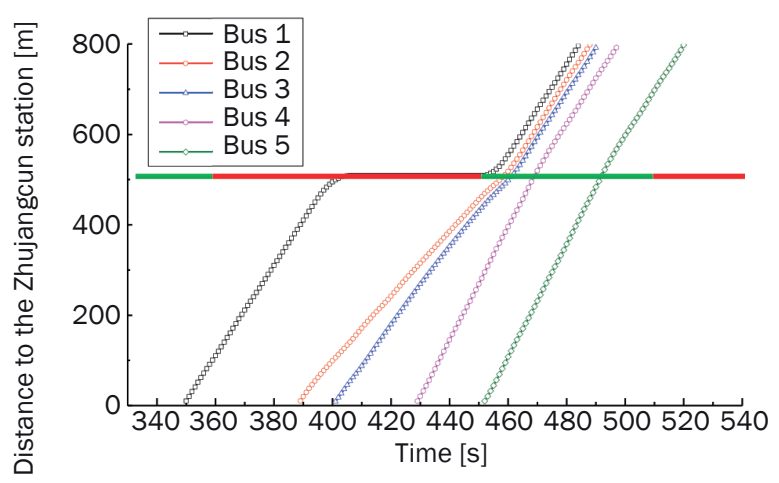

d) Typical bus trajectories with cooperative control

Figure 3 - BRT vehicle trajectories in different environments (in 30 mins) 


\subsection{Evaluation results}

Two scenarios including with and without the cooperative control model have been simulated in the same traffic condition. Each scenario has been run 10 times with different random speeds. The simulation results are shown in Table 2 and Figure 3.

The average number of stops of a BRT vehicle in two directions are reduced by $45 \%$ (from West to East) and $39.34 \%$ (from East to West) respectively. Meanwhile, the average delay time decreases by $7.23 \%$ (from West to East) and 5.19\% (from East to West), respectively. Furthermore, BRT vehicles could pass through the intersection more smoothly with the cooperative control model. Thus, the sustainability of the BRT vehicles is improved. The proposed model saves about 9.17\% fuel consumption of all buses from West to East, and $7.52 \%$ in the opposite direction. Finally, The $\mathrm{CO}$ emissions of the BRT vehicles are reduced about $7.93 \%$ and $6.88 \%$, respectively.

In order to verify whether the cooperative control model will cause adverse impacts on the BRT system, bus arrival rate is employed as the key parameter. The number of BRT vehicles arriving at the Xiasha station in each minute is shown in Figure 4. It shows that the proposed method has no significant impacts on the bus arrival rate.

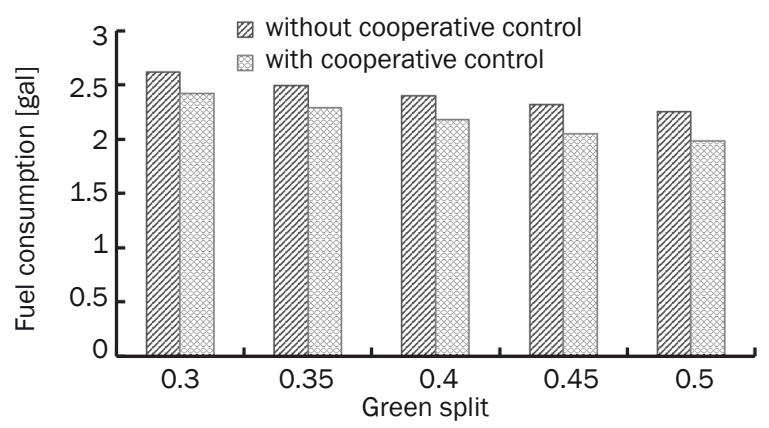

a) Fuel consumption

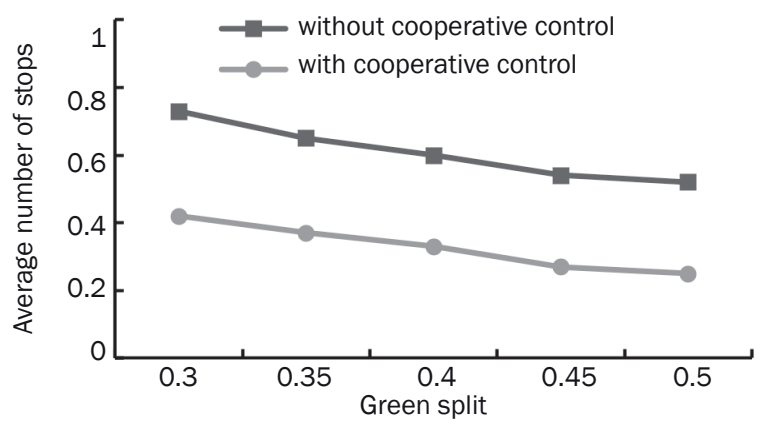

c) Average number of stops

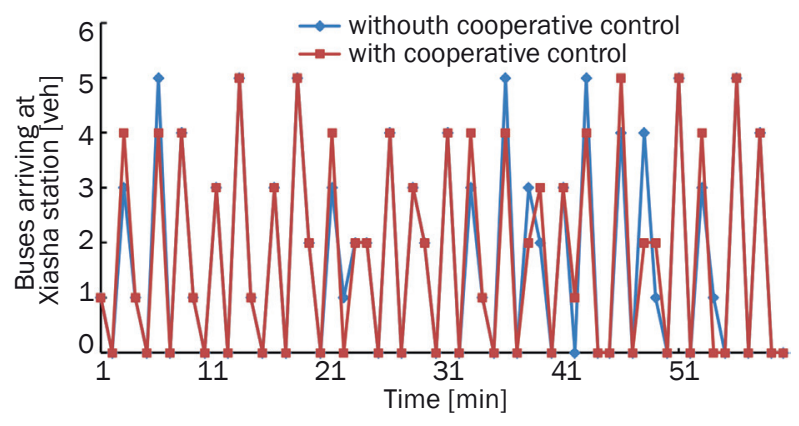

Figure 4 - Number of BRT vehicles arriving at the Xiasha station each minute

\subsection{Sensitivity analysis}

A sensitivity analysis is conducted to verify the effectiveness and scalability of the cooperative control model. The proposed model is evaluated in various green splits of the Zhongshan Avenue straight direction (denoted as $\lambda$ ), while the cycle length and phase sequence are fixed. Other than the actual ratio $\lambda=0.4$, four hypothetical scenarios are tested, including $\lambda=0.3, \lambda=0.35, \lambda=0.45$, and $\lambda=0.5$. The Zhongshan Avenue is the urban arterial road, and the Gangwan Road is a collector road. Therefore, it is reasonable that the green split of the Zhongshan Avenue straight direction varies from 0.3 to 0.5 . The sensitivity analysis results

The benefits of the cooperative control model increase with the incremental green split. The improvement of the delay time of the BRT vehicles from West

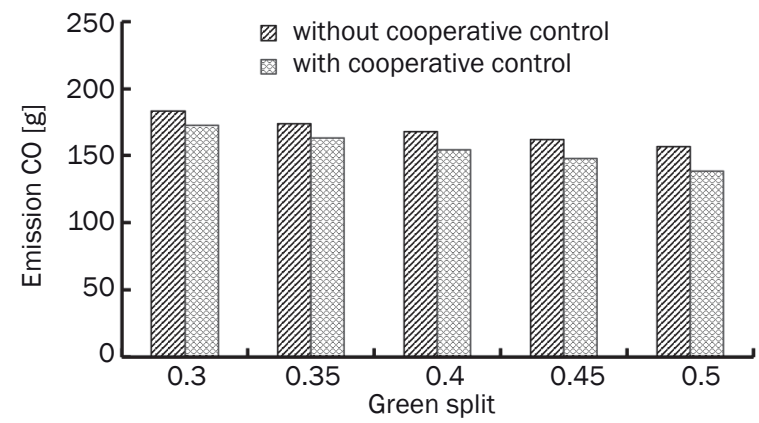

b) $\mathrm{CO}$ emissions

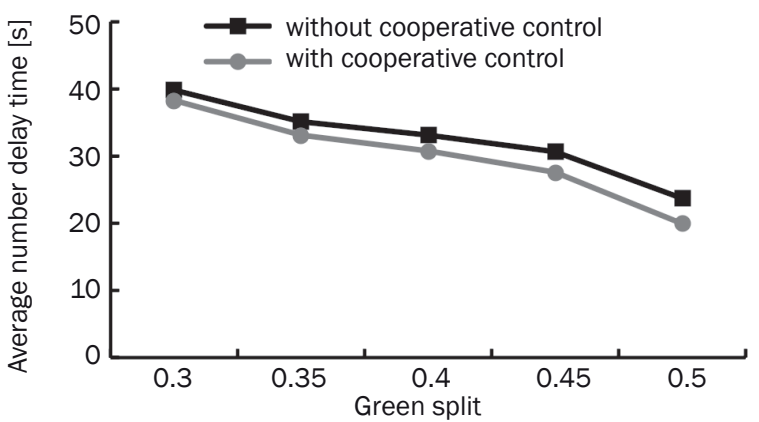

d) Average delay time

Figure 5 - Sensitivity analysis of the direction from West to East 


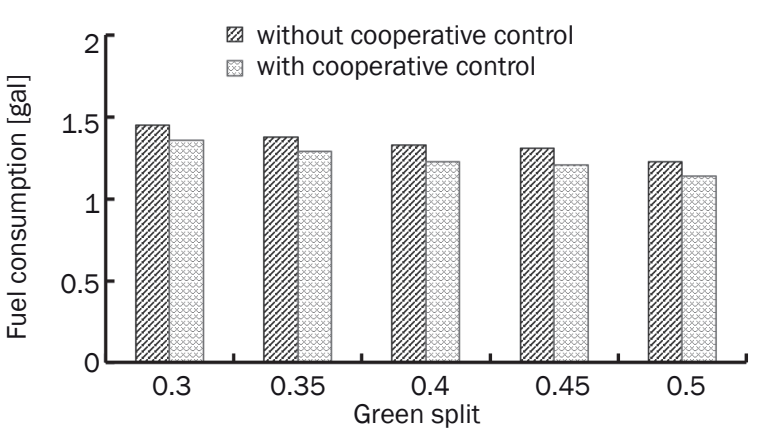

a) Fuel consumption

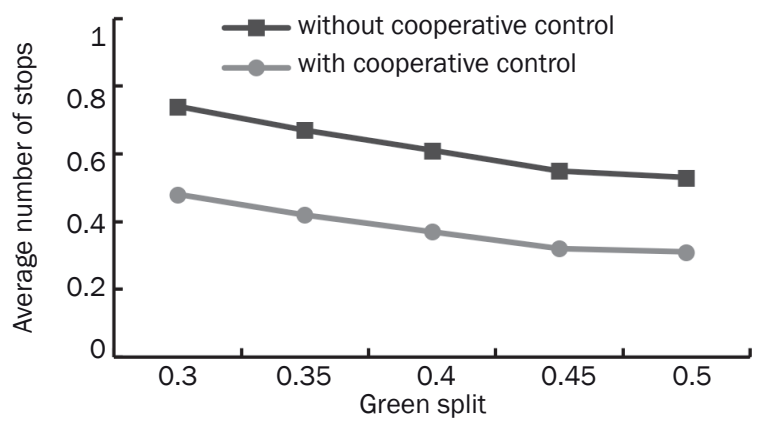

c) Average number of stops

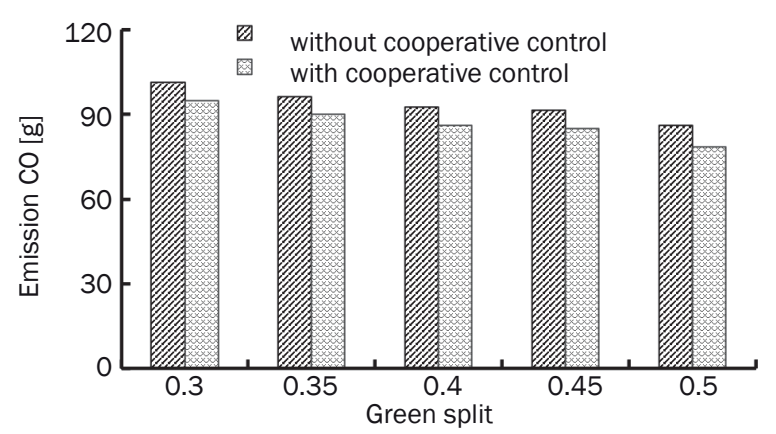

b) CO emissions

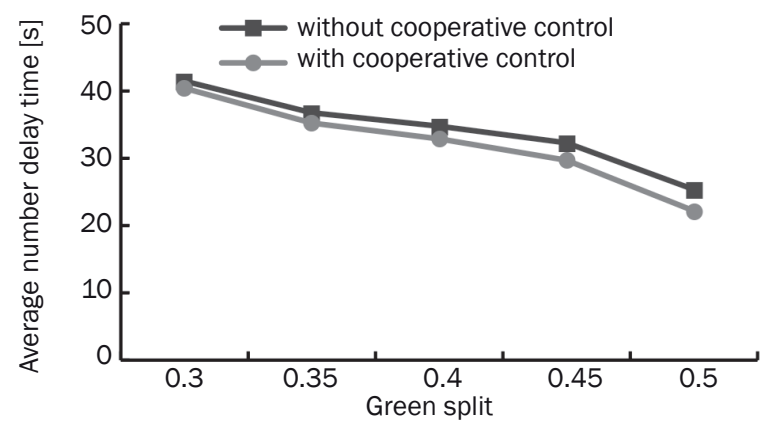

d) Average delay time

Figure 6 - Sensitivity analysis of the direction from East to West

to East gradually increases from $4.01 \%$ to $15.97 \%$. If the green split exceeds 0.45 , the stop probability of a BRT vehicle from West to East decreases from nearly $50 \%$ to about $25 \%$. That is because the extending reservation time interval allows more BRT vehicles to smoothly pass through the intersection with the cooperative control model. However, the reductions in $\mathrm{CO}$ emissions and the fuel consumption are not dramatic.

The evaluation indices of the BRT vehicles in both directions show similar tendency. The improvement of the delay time increases from $2.42 \%$ to $12.65 \%$. It suggests that the benefits of the cooperative control model in East-to-West direction are lower than those in the opposite direction. This should be attributed to the shorter distance from the Xiasha Station to the intersection and the narrower initial reservation time interval. If the green split is larger than 0.45 , about $70 \%$ of the BRT vehicles from East to West can pass through the intersection with no impedance. Finally, the optimization degree of $\mathrm{CO}$ emissions and fuel consumption both remain around $7.18 \%$.

\section{CONCLUSIONS AND FUTURE WORK}

This paper presents a cooperative control model for BRT vehicle platoon. CVC tries to distribute a specific reservation time interval for each BRT vehicle, and each vehicle will receive and follow the real-time instructions of the CVC. As a result, many BRT vehicles are guided to form a platoon that can pass through a signalized intersection with no impedance.
The simulation based evaluation results show that the proposed model can reduce the number of stops and the average delay time. The BRT vehicles' trajectories are smoothed to reduce fuel consumption and $\mathrm{CO}$ emissions. In other words, the proposed model improves the sustainability of BRT vehicles. Furthermore, a sensitivity analysis is conducted to verify the effectiveness and scalability of the cooperative control model. It is evaluated under various green splits of the phase for the dedicated bus lane. The simulation results show that even if the green split is relatively lower, the benefits of the proposed model are still considerable.

The proposed cooperative control model requires precise speed control method and excellent vehicle-to-vehicle and vehicle-to-infrastructure communication technologies. Fortunately, adaptive cruise control systems are a well-matured technology and are currently available on the market. In addition, the USDOT has already initiated the development and deployment of the connected vehicle technologies (formerly IntelliDrive technologies). New speed harmonization strategies are promising research areas. Therefore, the cooperative control model for BRT vehicle platoon is not an unattainable application. Future research should focus on assessing the performance of the proposed model in various road and traffic conditions, such as social vehicles' interference at nonpeak hours. Another possible extension of this study is combining the TSP with the cooperative control model in a connected vehicle environment. 


\section{ACKNOWLEDGEMENTS}

This work has been jointly supported by the $\mathrm{Na}$ tional Natural Science Foundation of China (NNSF) under Grant 61573149 and 61572233, the Transportation Foundation of Guangdong Province under Grant 2013-02-061 and 2015-02-062, and the Fundamental Research Funds for the Central Universities under Grant $2015 Z Z 008$.

刘佳辉

林培群

Peter J.Jin

\section{车联网环境下快速公交车队协同控制模型的建模 及仿真}

为了提高快速公交的运行效率，本文提出了车联 网环境下快速公交车队协同控制模型。建立了一个 车辆联网控制中心, 为每一辆公交车分配特定的预 定时间间隔和相应的动态速度引导。建立了一系列 约束条件, 避免公交车在下游BRT车站发生排队进 站、等待泊车的现象。因此, 若干快速公交车辆能 够形成一个车队, 并且不停车地通过信号交叉口。 选取广州市快速公交走廊的信号交叉口进行模型验 证，仿真结果表明：本文模型能够降低延误时间， 减少停车次数并提高快速公交的可持续性。

快速公交系统, 协同控制模型, 车联网, 车队

\section{REFERENCES}

[1] Levinso H, Zimmerman S, Clinger J, Rutherford S, Smith RL, Cracknell J, Soberman R. Bus rapid transit. Volume 1: Case Studies In Bus Rapid Transit. TCRP Report. Washington, D.C.: Transportation Research Board; 2003.

[2] Wright L, Hook W. Bus rapid transit: planning guide. Institute for Transportation and Development Policy (ITDP) [Internet]. 2007. Available from : http://reconnectingamerica.org/assets/Uploads/safe_routes_to_ transit_2005.pdf

[3] Maeso-González E, Pérez-Cerón P. State of art of bus rapid transit transportation. European Transport Research Review. 2014;6(2):149-156.

[4] Hafezi MH, Ismail A. A Comparative Analysis between Bus Rapid Transit and Regular Bus Operation. Australian Journal of Basic and Applied Sciences. 2012;6(13):216-220.

[5] Rakha H, Zhang Y. Sensitivity Analysis of Transit Signal Priority Impacts on Operation of a Signalized Intersection. Journal of Transportation Engineering. 2004;130:796-804.

[6] Dion F, Rakha H, Zhang Y. Evaluation of Potential Transit Signal Priority Benefits along a Fixed-Time Signalized Arterial. Journal of Transportation Engineering. 2004;130(3):294-303.
[7] Muthuswamy S, McShane WR, Daniel JR. Evaluation of Transit Signal Priority and Optimal Signal Timing Plans in Transit and Traffic Operations. Transportation Research Record: Journal of the Transportation Research Board. 2007;2034:92-102.

[8] Chen X, Yu L, Zhu L, Yu L, Guo J. Microscopic Simulation Approach to Effectiveness Analysis of Transit Signal Priority for Bus Rapid Transit: A Case Study in Beijing. Transportation Research Record: Journal of the Transportation Research Board. 2008;2072:64-76.

[9] Hu J, Park B, Parkany AE. Transit Signal Priority with Connected Vehicle Technology. Transportation Research Record: Journal of the Transportation Research Board. 2014;2418:20-29.

[10] Koonce P. Prioritizing Transit in a Connected Vehicle World. ITE Journal. 2012;82(12):18-22.

[11] Abu-Lebdeh G, Chen H. Development of a framework for an integrated dynamic signal-dynamic speed traffic management algorithm for signalized networks. Proceedings of the $85^{\text {th }}$ Annual Meeting of the Transportation Research Board. 2006 March 3; Washington DC, USA.

[12] Abu-Lebdeh G. Exploring the potential benefits of IntelliDrive-enabled dynamic speed control in signalized networks. Proceedings of the 89th Annual Meeting of the Transportation Research Board. 2010 January 25; Washington DC, USA.

[13] Abu-Lebdeh G. Integrated adaptive-signal dynamic-speed control of signalized arterials, Journal of Transportation Engineering. 2012;128(5):447-451.

[14] Yang Y, Chen S, Sun J. Modeling and Evaluation of Speed Guidance Strategy in VII System. Proceedings of the 13th International IEEE Conference on Intelligent Transportation Systems. 2010 September 19-22; Madeira Island, Portugal.

[15] Asadi B, Vahidi A. Predictive cruise control: Utilizing upcoming traffic signal information for improving fuel economy and reducing trip time. IEEE Transaction on Control Systems Technology. 2011;19(3):707-714.

[16] Mahler G, Vahidi A. An Optimal Velocity-Planning Scheme for Vehicle Energy Efficiency Through Probabilistic Prediction of Traffic-Signal Timing. IEEE Transaction on Intelligent Transportation Systems. 2014;15(6):2516-2523.

[17] Goodall NJ, Park B, Smith BL. Microscopic Estimation of Arterial Vehicle Positions in a Low Penetration-Rate Connected Vehicle Environment. Journal of Transportation Engineering. 2014;140(10):1027-1041.

[18] Lin P, Zhuo F, Yao K, Ran B, Xu J. [Solving and Simulation of Microcosmic Control Model of Intersection Traffic Flow in Connected-vehicle Network Environment]. China Journal of Highway and Transport. 2015;28(8):82-90. Chinese

[19] Lin P, Jin PJ, Ran B, Cheng Y, Hu H, Xu J. Cooperative Movement of Intersectional Traffic Flow in a Connected Vehicle Environment. Proceedings of 94th Annual Meeting of the Transportation Research Board. 2014 December 30; Washington DC, USA.

[20] VISSIM 5.20 COM User Manual. Karlsruhe, Germany: Planung Transport Verkehr (PTV); 2009. 